\title{
ASSOCIATION OF AGE, GENDER, STROKE LOCATION, AND SOCIAL SUPPORT WITH DEPRESSION AND COGNITIVE IMPAIRMENT AFTER STROKE
}

\author{
Fazal Ur Rahman Saeed, Sikandar Ali Khan*, Saeed Bin Ayaz ${ }^{* *}$
}

Armed Forces Institute of Rehab Medicine/National University of Medical Sciences (NUMS) Rawalpindi Pakistan, ${ }^{*}$ Combined Military Hospital Gujranwala/ National University of Medical Sciences (NUMS) Pakistan, ${ }^{* *}$ Combined Military Hospital Jhelum/National University of Medical Sciences (NUMS) Pakistan

\section{ABSTRACT}

Objective: To identify depression and cognitive impairment after stroke and analyze association with age, gender, stroke location, and social support.

Study Design: A cross-sectional analytical study.

Place and Duration of Study: Psychiatry and Rehabilitation Medicine, Combined Military Hospital Gujranwala, from Oct 2015 to Aug 2018.

Methodology: Patients (age: 20-80 years) with stroke $\geq 3$ months were included. Those with aphasia, unstable medical history, and coexisting other neurological disorder were excluded. Cognition was assessed by Montreal Cognitive Assessment (MoCA) and post-stroke depression (PSD) was assessed by Beck Depressive Inventory 2nd Edition (BDI-II).

Results: Out of 76 patients (meanage: $59 \pm 7$ years), 53 (69.7\%) were male and $23(30.3 \%)$ were females. Fifty-five (72.4\%) were of age $>55$ years and $58(76.3 \%)$ patients had social support. On MoCA evaluation, 41 (53.9\%) patients had cognitive impairment. BDI-II assessment showed that 43 (56.6\%) individuals had depression. A significantly higher percentage of males, patients without social support, and patients $>55$ years developed PSD with $p<0.05$. The cognitive deficit, was statistically significant in the age group of $>55$ years $(p=0.026)$ and no correlation with gender or presence/absence of social support was observed ( $p=0.088$ and $p=0.485$ respectively). Similarly, no significant correlation was found between stroke location and development of cognitive deficit or PSD ( $p=0.361$ and $p=0.390$ respectively).

Conclusion: Cognitive impairment and PSD were frequently present after stroke. PSD was more common in males, patients without social support, and patients of older age while cognitive deficit was more common in older age.

Keywords: Age factors, Association, Cognitive impairment, Depression, Stroke, Stroke location, Social support.

\footnotetext{
This is an Open Access article distributed under the terms of the Creative Commons Attribution License (https://creativecommons.org/licenses/by-nc/4.0/), which permits unrestricted use, distribution, and reproduction in any medium, provided the original work is properly cited.
}

\section{INTRODUCTION}

In elderly individuals, ability to carry out daily activities is very important as it indicates the functional capacity, which, if hampered, leads to disability, neuro -psychiatric morbidities, and mortality ${ }^{1}$. Stroke is associated with many physical, functional, and psychological problems in the elderly and leads to compromised daily life activities ${ }^{2,3}$. After stroke, some degree of cognitive impairment is present, irrespective of the severity of stroke ${ }^{3}$. Physical impairments occurring due to stroke tend to improve but due to unknown reasons, cognitive impairment tends to get worse progressive$1 y^{4}$. Cognitive impairment leads to deficits in attention, mental processing speed, visual perception, constructional ability 5 , and cognitive control that includes execution and inhibition responses in our daily routine. Furthermore, cognitive impairment is seen in any one domain rather than in multiple domains ${ }^{6}$. There are fifteen million people worldwide that suffer from stroke every year, out of whom thirty percent develop cognitive impairment ${ }^{6}$. Earlier, cognitive impairment after

Correspondence: Dr Fazal Ur Rahman Saeed, Classified Specialist Rehab Medicine, AFIRM Rawalpindi Pakistan

Received: 16 Apr 2019; revised received: 13 Oct 2019; accepted: 31 Oct 2019 stroke was considered as vascular dementia, but the concept has changed. It is now taken as vascular cognitive impairment because not all patients with cognitive impairment after stroke meet the criteria of dementia ${ }^{6}$.

After stroke, patients are more vulnerable to developcognitive impairment within first three months ${ }^{7}$. Chances of cognitive impairment increases many folds if the stroke has occurred after the age of sixty-five ${ }^{8}$. On the other hand, higher level of education has shown to be a protective factor ${ }^{9}$. Nature of job also has important part to play in the development of cognitive impairment such that the individuals working on administrative positions have more obvious cognitive decline than other jobs ${ }^{10}$. Other risk factors for the development of cognitive impairment after stroke are smoking, hypertension, hyperlipidemia, diabetes mellitus, atrial fibrillation, and existing cerebral lesions. Cognitive impairment is a grave and significant consequence of stroke, that not only affects the course of the disease but is also responsible for many mishaps that are attributed to defective attention and deficient decision power.

Depression is the commonest psychological disorder after stroke and affects approximately 30\% of the 
patients. In spite of a well-understood relationship of post-stroke depression (PSD) with worse functional consequences, reduced quality of life, and increased mortality, its pathogenesis is inadequately appreciated $^{12}$. More than half of all cases are neither diagnosed nor treated ${ }^{13}$. As PSD has a complex etiology, it cannot be prevented, nevertheless, the process can be limited and its harm can be reduced ${ }^{13}$. The state of mind and quality of life can be improved and the possibility of medical complications including relapse can be reduced $^{10}$.

So far, there is deficiency in local data about prevalence and pattern of cognitive deficits and PSD among stroke survivors in Pakistan. The objective of this study was to determine the frequency of cognitive deficiency and PSD in patients who presented to a tertiary care health facility in Gujranwala. The secondary objectives were to find any relation of prevalence of cognitive deficit and PSD with age, gender, the location of stroke, and the availability of social support.

\section{METHODOLOGY}

It was a cross-sectional analytical study conducted at the departments of psychiatry and rehabilitation medicine, Combined Military Hospital Gujranwala, from October 2015 to August 2018. A total of seventysix subjects were included by using consecutive nonprobability sampling after the approval from the ethics committee. After written consent, all inductees were explained purpose of the study and confidentiality was ensured. The inclusion criteria were: a) stroke occurring at least 3 months prior to enrolment, b) age 20-80 years, c) enough knowledge of English reading and writing prior to stroke d) able to follow the study instructions. The exclusion criteria were: a) unstable medical history e.g. recent myocardial infarction, that might limit participation, b) aphasic subjects c) concomitant other neurological disorder such as Parkinson's disease, Amyotrophic lateral sclerosis, and multiple sclerosis.

The cognitive impairment was evaluated with Montreal Cognitive Assessment (MoCA) version 7.1. MoCA is a rapid screening instrument for mild cognitive dysfunction. It gauges the areas of attention, concentration, executive function, memory, language, visioconstructional skills, conceptual thinking, calculation, and orientation. Generally, it is completed within ten minutes. The total possible score is 30 and a score of 26 or more is considered normal. The reliability and validity of MoCA is established for patients with stroke. The location of stroke was ascertained by computed tomographic scan of the brain as recommended by Ihsan et al11-14.

Detailed judgement and diagnosis of PSD was carried outaccording tothe diagnostic criteria given by the International Classification of Diseases version 10 and symptom severity was assessed using Beck Depressive Inventory 2nd Edition (BDI-II) for depression. BDI-IIconsists of 21 questions, each with four probable answers that are allotted a score ranging from 0-3. Better scores point towards more severe symptoms. Total score is obtained by adding individual scores of 21 items. Total score ranges from $0-63$. Scores of 0-13 indicate minimal depression, 14-19: mild depression, 2028: moderate depression, and scores of 29-63 signify severe depressive symptoms.

Data analysis was performed using Statistical Package for Social Sciences version 20. The data were described as averages (mean $\pm \mathrm{SD}$ ) and percentages (frequency and \%). For statistical analysis, Pearson's Chisquare test was used. All the inferences were made at $95 \%$ confidence interval and $p$-values of $\leq 0.05$ were considered significant.

\section{RESULTS}

A total of 76 patients were included in this study. The mean age was $59 \pm 7$ years with a range from $45-69$ years. Fifty-three $(69.7 \%)$ were male (mean age: $60 \pm 6$ years, range: $45-69$ years) and $23(30.3 \%)$ were female (mean age: $55 \pm 6$ years, range: $45-63$ years). All inductees in the sample were married. Twenty-one $(27.6 \%)$ patients were $\leq 55$ years of age while $55(72.4 \%)$ were of age $>55$ years. Fifty-eight $(76.3 \%)$ had social support while $18(23.7 \%)$ were without social support.

Sixteen $(21.1 \%)$ patients did not have a risk factor for the development of stroke while 60 (78.9\%) had one or multiple risk factors for the development of stroke. The commonest risk factor was smoking reported by $28(36.8 \%)$ patients. This was followed by hypertension and diabetes reported by $10(13.2 \%)$ and four (5.3\%) patients respectively. Eighteen (23.7\%) individuals had multiple risk factors for the development of stroke.

The commonest location of the stroke was left cerebral hemisphere found in $27(35.5 \%)$ patients. Nineteen $(25 \%)$ patientshad involvement of the right cerebral hemisphere. In $17(22.4 \%)$ patients there were multiple lacunar strokes in the brain substance while in $13(17.1 \%)$, a brain stem stroke was found.

On MoCA evaluation, 41 (53.9\%) patients had cognitive impairment while $35(46.1 \%)$ had normal cognition. BDI-II assessment showed that 43 (56.6\%) 
individuals had depression while 33 (43.4\%) individuals did not have depressive symptoms. On evaluation of the effect of age group, gender, and social support on cognitive deficit and depression, a significantly larger number of males, patients without social support, and patients $>55$ years developed PSD than females, patients with social support, and patients with age $\leq 55$ years $(p<0.05)($ table-I).

The cognitive deficit, on the other hand, was statistically significant in the age group of $>55$ years $(p=0.026)$, while no statistically significant correlation with gender or presence/absence of social support was observed ( $p=0.088$ and $p=0.485$ respectively). Similarly, no statistically significant correlation was found between the location of stroke and development of cognitive deficit or PSD ( $p=0.361$ and $p=0.390$ respectively) (table-II). age of 67 years $^{13}$. Thus, more or less, stroke is a disease of the middle-aged people and appropriate mass education program regarding the preventive strategies should be the part of our health system procedures to reduce its prevalence in our country.

Our study has shown that cognitive impairment was present in $53.9 \%$ of individuals with stroke. These results were in accordance with the results of studies by Nguyen et $a l^{5}$. Terroni et al17, and Wang et al ${ }^{18}$, which indicated incidence of cognitive impairment after stroke ranging from $12-87 \%$. Our study has shown a high frequency of $56.6 \%$ for the PSD in our study population. Arauz et al ${ }^{16}$, also reported a prevalence of $56 \%$ for PSD in a Mexican cohort. The most-quoted studies of prevalence and incidence of PSD in the recent past have utilized meta-analysis to create large databases 19,20. A meta-analysis of 61 cohorts carried out in 2014,

Table-I: Interaction of age group, gender, and presence/absence of social support with presence of cognitive deficit and depression.

\begin{tabular}{|c|c|c|c|c|c|c|}
\hline \multirow{2}{*}{ Characteristics } & \multicolumn{2}{|c|}{ Cognitive Deficit } & \multirow{2}{*}{$p$-value } & \multicolumn{2}{|c|}{ Depression } & \multirow{2}{*}{$p$-value } \\
\hline & Present, n (\%) & Absent, n (\%) & & Present, n (\%) & Absent, n (\%) & \\
\hline \multicolumn{7}{|l|}{ Age Group } \\
\hline$\leq 55$ years & $7(33.3)$ & $14(66.7)$ & \multirow{2}{*}{0.026} & $8(38.1)$ & $13(61.9)$ & \multirow{2}{*}{0.045} \\
\hline$>55$ years & $34(61.8)$ & $21(38.2)$ & & $35(63.6)$ & $20(36.4)$ & \\
\hline \multicolumn{7}{|l|}{ Gender } \\
\hline Male & $32(60.4)$ & $21(39.6)$ & \multirow{2}{*}{0.088} & $34(64.2)$ & $19(35.8)$ & \multirow{2}{*}{0.043} \\
\hline Female & $9(39.1)$ & $14(60.9)$ & & $9(39.1)$ & $14(60.9)$ & \\
\hline \multicolumn{7}{|l|}{ Social Support } \\
\hline Present & $30(51.7)$ & $28(48.3)$ & \multirow{2}{*}{0.485} & $29(50)$ & $29(50)$ & \multirow{2}{*}{0.038} \\
\hline Absent & $11(61.1)$ & 7 (38.9) & & $14(77.8)$ & $4(22.2)$ & \\
\hline
\end{tabular}

Table-II: Table showing interaction of location of stroke with presence of cognitive deficit and depression.

\begin{tabular}{|c|c|c|c|c|c|c|}
\hline \multirow{2}{*}{ Characteristics } & \multicolumn{2}{|c|}{ Cognitive Deficit } & \multirow{2}{*}{$p$-value } & \multicolumn{2}{|c|}{ Depression } & \multirow{2}{*}{$p$-value } \\
\hline & Present, $\mathrm{n}(\%)$ & Absent, n (\%) & & Present, n (\%) & Absent, n (\%) & \\
\hline \multicolumn{7}{|c|}{ Location of Stroke } \\
\hline $\begin{array}{l}\text { Right cerebral } \\
\text { hemisphere }\end{array}$ & $10(52.6)$ & $9(47.4)$ & \multirow{4}{*}{0.361} & $10(52.6)$ & $9(47.4)$ & \multirow{4}{*}{0.390} \\
\hline $\begin{array}{l}\text { Left cerebral } \\
\text { hemisphere }\end{array}$ & $18(66.7)$ & $9(33.3)$ & & $18(66.7)$ & $9(33.3)$ & \\
\hline Lacunar & $7(41.2)$ & $10(58.8)$ & & $7(41.2)$ & $10(58.8)$ & \\
\hline Brainstem & $6(46.2)$ & $7(53.8)$ & & $8(61.5)$ & $5(38.5)$ & \\
\hline
\end{tabular}

\section{DISCUSSION}

The mean age of our studied sample was 59 years with a range of 45-69 years. This mean age was similar to the mean ages of two stroke groups (59.2 \pm 13.3 years and $56.7 \pm 11.7$ years) in a previous study carried out in Rawalpindi on stroke patients to compare the effects of early and delayed rehabilitation ${ }^{15}$. Another studyfrom the same centeron stroke patients revealed a little higher mean age of 63 yearsin $2016^{2}$. A Mexican study on stroke survivorshad observed a mean age of 56 years $^{16}$, and a Chinese study reported a higher mean including 25,488 patients ${ }^{19}$, reported that $31 \%$ of the patients developed depression at any time point up to 5 years following stroke. A prior meta-analysis of 43 studies published in 2013 included 20,293 patients and reported that the pooled prevalence of PSD was $29 \%$ at any time point within 5 years following stroke ${ }^{20}$.

We found that elderly people were having more chances to develop PSD than younger people. Alajbegovic et al21, on the contrary, reported that younger patients (51-60 years) had higher depression scores compared to the older (61-70 years) population. The 
frequency of PSD was $39.2 \%$ in younger people and $32 \%$ in the older people that was statistically significant $(p<0.05)$. Jiang et al ${ }^{13}$, similar to our study, found that stroke patients in the age group of $>60$ years were having higher chances to develop PSD. They mentioned the reason behind this association that due to declining bodily functions and biochemical changes in human brain i.e. an increase in monoamine oxides and a decrease in 5-hydroxytryptamine and norepinephrine, older people ( $>60$ years old) are more likely to have PSD than younger counterparts after stroke.

Many researchers have examined the gender differences among stroke survivors for depression. Alajbegovic et al21, in a study from Bosnia and Herzegovina and Jiang et $a l^{13}$, in a review suggestedthat women were more likely to experience depression after stroke ( male to female ratio $=1: 2.3$ and approximately 1:2.6 respectively) and this happened because they felt increasingly helpless against the physiological and social pressure factors and, in this way, lost psychological balance more easily after stroke than men ${ }^{13,21}$. The other analysts had discovered that men had an equivalent or significantly more opportunities to have PSD ${ }^{13}$. We found that men were significantly more prone to develop PSD but not the cognitive impairment after stroke than women. The reason behind this disparity is probably that the economic responsibility of the family primarily lies with men. This coupled with huge stresses in life make the middle aged-men more liable to develop PSD especially when they suffer a sudden setback after stroke.

Specificity and severity of the brain region involved in stroke is important for the development of cognitive impairment ${ }^{18}$. Though this study did not find any association of site of the brain area involved with development of cognitive impairment and PSD but it is noteworthy that in $35 \%$ patients with PSD, left cerebral hemisphere, and in 25\%, right cerebral hemisphere was involved. Previous studies have shown that changes in mood and emotions are closely associated with the area of brain involved 22 . According to some researchers, damage to the left basal ganglia and left dorsolateral and frontal region of the cortex was purportedly responsible for $\mathrm{PSD}^{23}$. Numerous other investigations have later certified this affiliation. Some examiners ${ }^{24}$, discovered that injury to the right basal ganglia and right lateral frontal lobewere significantly less likely to cause PSD than similar lesions on the left side. Be that as it may, a few other studies did not confirm this association. In this way, and given that obser-vations from different studies are opposing, mainly because of methodological biases, we can infer that the evidence is insufficient to verifya relationship between lesion laterality and risk of developing PSD.

Lack of social support and/or general selfefficiency play important role in the development of depression in patients of stroke.Robinson $e t$ al25, found that lack of social support at admission was associated with the onset of PSD at 3-months follow-up $25 \mathrm{Volz}$ et $a l^{12}$, concluded that perceived social support exerted protective influence on later PSD $(\mathrm{OR}=0.95, p=0.03)$ six months post-stroke. However, the available evidence concerning PSD and social support is conflicting, probably because of significant heterogeneity in the definition and evaluation of social support. Even in the presence of social support, if the general self-efficiency is reduced after stroke, there is higher risk of development of PSD23,24. This study shows that social support was available to $76.3 \%$ of the patients but still $56 \%$ of patients developed PSD. These results highlight the fact that these patients did have social support but probably developed PSD due to reduced general selfefficacy that was not assessed in this study.

In closing remarks, we proposed that recovery after stroke ought to be tended more specifically throughout rehabilitation. Not only physical but also psychological evaluation needs importance and treatment as they are bread and butter for each other. There is a need to involve all stakeholders and employ a coordinated approach with short and long-term goals. This should include the physicians (neurologists, rehabilitation medicine physicians, and psychiatrists), allied health care professionals (physiotherapists, occupational therapists, speech and language therapists, psychologists, and social workers, etc.), patients, and their caregivers. A harmonized effort would bring better outcome in all aspects of bodily functions after stroke-induced disability.

\section{LIMITATION OF STUDY}

Due to a small sample size, the statistical power of this study was reduced. Social support was not well-defined in this study. Furthermore, post-stroke assessment for cognitive impairment and PSD were not graded and only presence and absence were mentioned.

\section{CONCLUSION}

After stroke cognitive impairment and depression are frequently present that are neither recognized nor diagnosed. PSD was more common in males, patients without social support, and patients of older age while 
cognitive deficit was more common in older age. Based on the result of this study and current knowledge it is suggested that non psy-chiatric patients having stroke, need to be assessed and monitored for the development of depression and cognitive impairment for early diagnosis and better management.

\section{CONFLICT OF INTEREST}

This study has no conflict of interest to be declared by any author.

\section{REFERENCES}

1. Oros RI, Popescu CA, Iova CA, Mihancea P, Iova SO. The impact of cognitive impairment after stroke on activities of daily living. Hum Vet Med 2016; 8(1): 41-44.

2. Akhlaq U, Ayaz SB, Akhtar N, Khan AA. Frequency and intensity of shoulder pain after stroke: a hospital based study. Pak Armed Forces Med J 2016; 66(1): 71-4.

3. Tang EYH, Price C, Stephan BCM, Robinson L, Exley C. Gaps in care for patients with memory deficits after stroke: views of healthcare providers. BMC Health Serv Res 2017; 17(1): 634-36.

4. Nakling AE, Aarsland D, Næss H, Wollschlaeger D, Fladby T, Hofstad H, et al. Cognitive Deficits in Chronic Stroke Patients: Neuropsychological Assessment, Depression, and Self-Reports. Dement Geriatr Cogn Dis Extra 2017; 7(2): 283-96.

5. Nguyen LT, Mudar RA, Chiang HS, Schneider JM, Maguire MJ, Kraut MA, et al. Theta and Alpha Alterations in Amnestic Mild Cognitive Impairment in Semantic Go/NoGo Tasks. Front Aging Neurosci 2017; 9(1): 160-64.

6. Sun JH, Tan L. Post-stroke cognitive impairment: epide-miology, mechanisms and management. Ann Transl Med 2014; 2(8): 80-83.

7. Sachdev PS, Brodaty H, Valenzuela MJ, Lorentz L, Looi JC, Berman K, et al. Clinical determinants of dementia and mild cognitive impairment following ischaemic stroke: the Sydney Stroke Study. Dement Geriatr Cogn Disord 2006; 21(5-6): 275-83.

8. Gorelick PB, Scuteri A, Black SE, Decarli C, Greenberg SM, Iadecola $\mathrm{C}$, et al. Vascular contributions to cognitive impairment and dementia: a statement for healthcare professionals from the American heart association/American stroke association. Stroke 2011; 42(9): 2672-13.

9. Wu Y, Wang M, Ren M, Xu W. The effects of educational background on montreal cognitive assessment screening for vascular cognitive impairment, no dementia, caused by ischemic stroke. J Clin Neurosci 2013; 20(10): 1406-10.

10. Douiri A, Rudd AG, Wolfe CD. Prevalence of poststroke cognitive impairment: South London Stroke Register 1995-2010. Stroke 2013; 44(1): 138-45.

11. Sibolt G, Curtze S, Melkas S, Putaala J, Pohjasvaara T, Kaste M, et al. Poststroke dementia is associated with recurrent ischaemic stroke. J Neurol Neurosurg Psychiatry 2013; 84(7): 722-26.

12. Volz M, Möbus J, Letsch C, Werheid K. The influence of early depressive symptoms, social support and decreasing self-efficacy on depression 6 months post-stroke. J Affect Disord 2016; 206(1): 252-55.

13. Jiang XG, Lin Y, Li YS. Correlative study on risk factors of depression among acute stroke patients. Eur Rev Med Pharmacol Sci 2014; 18(9): 1315-23.

14. Ihsan HR, Ahmad S, Ayaz SB. The spectrum of radiological findings in patients presenting with different clinical indications for cranial computed tomographic scan. Pak Armed Forces Med J 2019; 69(1): 170-74.

15. Fahim M, Waheed A, Ahmad K, Shah SS. Comparing rehabilitation outcome in stroke patients, presenting within and after three months post stroke. Pak Armed Forces Med J 2013; 63(1): 68-71.

16. Arauz A, Rodríguez-Agudelo $\mathrm{Y}$, Sosa AL, Chávez M, Paz F, González M, et al. Vascular cognitive disorders and depression after first-ever stroke: the Fogarty-Mexico Stroke Cohort. Cerebrovasc Dis 2014; 38(4): 284-89.

17. Terroni L, Sobreiro MFM, Conforto AB, Adda CC, Guajardo VD, de Lucia MCS, et al. Association among depression, cognitive impairment and executive dysfunction after stroke. Dement Neuropsychol 2012; 6(3): 152-57.

18. Wang Y, Wang Y, Ma W, Lu S, Chen J, Cao L. Correlation between cognitive impairment during the acute phase of first cerebral infarction and development of long-term pseudobulbar affect. Neuropsychiatr Dis Treat 2018; 14(): 871-77.

19. Hackett ML, Pickles K. Part I: frequency of depression after stroke: an updated systematic review and meta-analysis of observational studies. Int J Stroke 2014; 9(8): 1017-25.

20. Ayerbe L, Ayis S, Wolfe CD, Rudd AG. Natural history, predictors and outcomes of depression after stroke: systematic review and meta-analysis. Br J Psychiatry 2013; 202(1): 14-21.

21. Alajbegovic A, Djelilovic-Vranic J, Nakicevic A, Todorovic L, Tiric-Campara M. Post stroke depression. Med Arch 2014; 68(1): 47-50.

22. Wang G, Teng F, Chen Y, Liu Y, Li Y, Cai L, et al. Clinical features and related factors of poststroke pathological laughing and crying: a case-control study. J Stroke Cerebrovasc Dis 2016; 25(3): 556-64.

23. EspárragoLlorca G, Castilla-Guerra L, Fernández Moreno MC, Ruiz Doblado S, Jiménez Hernández MD. Post-stroke depression: an update. Neurol 2015; 30(1): 23-31.

24. Herrmann N, Black SE, Lawrence J, Szekely C, Szalai JP. The sunnybrook stroke study: a prospective study of depressive symptoms and functional outcome. Stroke 1998; 29(3): 618-24.

25. Robinson RG, Jorge RE. Post-stroke depression: a review. Am J Psychiatr 2016; 173(3): 221-31. 